\title{
TOWARD CONCEPTUALIZATION OF AN EMERGENT FORM: EXOTOURISM
}

\author{
Marius-Cristian Neacșu \\ Bucharest University of Economic Studies, Romania, marius.neacsu@ase.ro
}

\begin{abstract}
This study represents an exploratory research, which aims to create an incipient theoretical framework for conceptualizing a new notion, namely that of exotourism. The new cosmic competition, which is different from the one during the Cold War, through its commercial and private character, generated a phenomenology associated with a new form of tourism, respectively trips for recreational purposes in the space, with private character, for which we propose the term 'exotourism'. Thus, as objectives of this exploratory research we mention: testing a working definition, critical analysis of terminology and identifying the essential characteristics of exotourism, which would give scientific legitimacy to exotourism, as well as the emerging concept.
\end{abstract}

Keywords:

Exotourism, exotourist, astrotourism, space tourism, New Space Race

JEL Classification: L83, M13, Z32

DOI: $10.24818 / \mathrm{CTS} / 3 / 2021 / 2.09$

\section{Introduction}

The phenomenological context. In a current study (Neacșu and Matei, in press) we pointed out that humanity has entered an accentuated spatial phase of history, the fourth after the terrestrial one, maritime/oceanic and aerial, in the last two years, despite the COVID-19 pandemic, being relaunched the space race, with many novelty elements, compared to the one during the Cold War, namely: a) it is a competition with many more actors and not just state ones; b) several private companies, with a great financial and technological capacity, are involved in space flights, unprecedented in history, having launch sites, missiles and space capsules of their own manufacture, etc.; c) we are witnessing a real privatization and commercialization of space flights (through the involvement of eccentric billionaires); d) NASA itself (dependent on the public budget, so by the political decision) became a simple customer in the new space age, sending astronauts to the International Space Station (ISS) with the help of a private infrastructure; e) space missions are no longer eminently governmental, being initiated the first private space travel.

For example, 2021 marks 20 years, an anniversary moment therefore, since the first earthling that came out into space (on the ISS on April 30, 2001), for tourist purpose, traveling aboard the Russian Soyuz rocket: it is about the well-known American millionaire, of Serbian origin, Denis Tito, who afterwards stated: "It was the greatest moment of my life" (Street, 2021).

Two decades later, the British billionaire Richard Branson (Virgin Group CEO) flew with his space plane (Virgin Galactic) on July 11, 2021, at an altitude of $85 \mathrm{~km}$, experiencing imponderability (zero gravity) - "a lifetime experience" (Amos , 2021), and Jeff Bezos (Amazon CEO) was propelled by his company's (reusable) New Shepard rocket (Blue Origin) on July 20 (at exactly 52 years after the Apollo 11 mission and its successful landing), at $106 \mathrm{~km}$ altitude, in a capsule that would become "best day ever" (Rincon, 2021). The latter one also set two age records of the participants (an 18-year-old student and an 82-year-old veteran astronaut). 
Being a matter of "space travels" and not "missions in space", their reaction, mentioned above, which indicates the purely tourist motivation - living an experience in space for their own curiosity and pleasure - specifies that we are dealing with space tourists.

In addition, other space flights, with many unique elements, are already planned. For example, for the year 2023, a flight of the Japanese billionaire Yusaku Maezawa is scheduled on a singular loop around the Moon, which means, for the first time, a private trip beyond the high Earth orbit. And his motivation leaves no shadow of doubt about the idea, whether it is about space tourism - for which, in this study, we suggest the term of exotourism - or not: "I am so curious as to what's life like in space" (Space Adventures, 2021). Respectively, living the proper experience on an individual level (without a scientific or professional motivation), which, as a form, brings it closer to adventure tourism (extreme experience). Returning to Denis Tito, the first space tourist (exotourist), two decades ago mentioned, at that time, the euphoria: "It was eight days of euphoria" (Street, 2021).

The academic context. Given these new realities, it was essential for the phenomenology in manifestation to be captured in the academic debates, followed by a conceptual crystallization. For example, for several years, within the MA Geopolitics and Business - former Geopolitics and International Affairs, within Bucharest University of Economic Studies, several studies have been designed (Șapera, 2015; 2013; Neacșu and Matei, in press) and some webinars have been organized (Şapera, 2021) that imposed in the specialized literature a series of terms, some of which, for the first time, are in relation with the emergence of the new post-Cold War space race. Consequently, a first term was that of exoeconomics (Șapera, 2013), which "will analyze the extraplanetary operations of production, distribution and consumption of goods and services within a man-made structure, for a settlement or a colony, which engages in economic activities (such as mining or "manufacturing"), located in outer space... so, an extraplanetary economy" (Șapera, 2015, p. 360).

The terminological context (theoretical). As a consequence, other specialized terms have evolved from exoeconomics to capture certain aspects of the human emergence in the circumplanetary space, such as exobusiness (proposed, for the first time, within the institution which was mentioned above), which, synthetically, "represents all the business performed in space industry (Space 4.0), either on Earth (logistics and idea laboratories for the space industry), or outside it (component of the extraplanetary economy or exoeconomy)" (Neacşu and Matei, in press). Obviously, other concepts have been developed, such as exopolitics ("derived from geopolitics in outer space, which studies the space powers, the power games and the power relations, how the control of space strategic points maximizes the power of a space actor" - Ibidem) or exostrategy ("control of critical points whose control can provide military and political domination over outer space" - Ibidem).

The purpose of this study, therefore, derives from the contexts presented above, and represents the attempt to theoretically conceptualize a new notion and term, respectively exotourism (with its derivative exotourist). Thus, the main targets are: testing a working definition, critically analyzing the terminology and identifying the essential characteristics of exotourism, which would give scientific legitimacy to exotourism, as well as to the emerging concept.

The novelty of the research is prominent, all these notions capturing an ongoing phenomenology, in an accentuated dynamics. Thus, on September 15, 2021, for the first time in the history of mankind and of tourist travel, four "civilians" flew into orbit, at an altitude higher than the ISS, the flight being operated by the private company SpaceX (Elon Musk), using a capsule (Crew Dragon, self-made, the first commercial spaceship to send NASA astronauts to space, first used for exotourism) and a self-made rocket,

Falcon 9 (the only alternative to Soyuz rockets, after the withdrawal of American spaceships since 2011). By "civilian" we understand "with no professional space experience, although the crew has undergone basic training to get a sense of what to expect" (Howell, 2021).

This orbital journey, with a significant name, Inspiration 4, which officially opened the era of exotourism, also allowed the realization of a potential profile of future exotourists, based on the analysis of crew members (Howell, 2021): 50\% male/female, an average age of 40-years-old, predominantly American citizens, entrepreneurs or with professions in the fields of medicine, engineering, science. 
The originality of this study also derives from the one above. It proposes a new working terminology and an attempt to theorize the notion of exotourism, with its derivatives.

The applicability is clear, both in the theoretical field, where there are at least two previous phrases with more or less close meanings, sometimes slightly confusing - astrotourism and space tourism - and in the practical one, given that the emergence of the new spatial phase of mankind, even in the case of exotourism, will be doubled by a legislative evolution of travel insurances, to give just two examples, in which the terminology is important.

\section{Literature review}

\subsection{Ambiguities regarding the definition: astrotourism (astronomical tourism) or space tourism?}

So far, the literature has retained two main expressions, specifically: "astrotourism" (sometimes also written "astro-tourism") and "space tourism", to capture everything that is related to the tourist approach of the cosmic process and phenomena, without distinguishing whether the tourist is on the surface of the planet (and he only enjoys observing a solar eclipse) or is in outer space, aboard a spacecraft.

Regarding to definitions, the literature records either a synonymy between the two terms, or a clear distinction, related to the place where the tourist is, on Earth or outside the Earth.

In consequence, space tourism is defined as "the practice of traveling into space for recreational, leisure, or business purposes", in summary "space for fun" (Stimac, 2020; Wilson, 2019, pp. 819-821), with the mention that, in this case, space tourism is more of a context than a form in itself, incorporating "terrestrial space tourism activities" (!), such as observing solar eclipses, meteor and meteoric shower, participating at rocket launches into outer space, admiring the polar auroras or simply the stargazing and making astronomical observations.

Furthermore, emphasizing the ambiguities in the definition of astrotourism, Pásková, Budinská and Zelenka (2021) "aspire to propose its complex definition as an activity including both terrestrial astrotourism and space tourism", the authors making a complex, yet suggestive mental map of astrotourism, in which the two sets of activities - terrestrial and space - bear the following names: "terrestrial astrotourism" and "space tourism". So, in this case, the space tourism becomes a component of astrotourism and not an emerging, independent form of tourism.

\subsection{Definitions and terminology}

In most cases, however, the two phrases involve definitions, which ensure the distinctiveness of the set of activities that fall within the field of the two notions, astrotourism including the terrestrial dimension of tourist activities, referring on the cosmic phenomenology, and space tourism on what it entails space travel.

Thus, Fayos Solá, Marín and Jafari (2014, p. 663) define astrotourism as "activity of travelers wishing to use the natural resource of well-kept night-scapes for astronomy-related leisure and knowledge" (implying, in advance, a journey on the surface of the planet), while other authors have a much more static perspective: "Astro-tourism is a tourism activity with astronomical phenomena or facilities as the main attraction" (Kunjaya, et al., 2019). And: "Astro-tourism comprises recreational and/or educational activities which are developed around the cosmos, astronomical phenomena and the ways of understanding them, both past (e.g. cosmogonies, mythologies, etc.) and present, including the latest scientific findings as well as the instruments and technologies that astronomers use in astronomy nowadays" (Verdi, 2015 cited in International Astronomical Union, 2021, p. 18).

Also, astrotourism is the "next big-thing" (Altschuler, 2019), "stars tourism" (Starlight, n.d. cited in Starlight Conference, 2021), "night-sky tourism" (Eskins, 2021), "the next big travel trend" or "the next frontier of nature-based tourism" in a post-COVID world (Singh, 2021), the last author using a more plastic definition, but with a certain semantic meaning: "The amalgamation of astronomy and tourism today has paved the way for a more sustainable and responsible form of travel i.e. astro-tourism" (Ibidem). In addition, an analysis of the phenomenology related to astrotourism, respectively motivations, experiences, perceptions of the participants, can be explored in the study Pásková, Budinská and Zelenka (2021). 
We reveal a first conclusion, respectively that astrotourism, from the perspective of this research, is nothing more than a form of tourism, calling it in a classic way (despite the abundant exuberant labels in the specialized literature) or conventional (Fayos Solá, Marín and Jafari, 2014, p. 669), which involves traveling in order to make astronomical observations (out of passion, not necessarily professional) and is currently experiencing some recovery, namely a tourist package that includes science, technology, tourism and hospitality.

However, the way astrotourism is perceived in various studies is varied: an alternative form or a niche tourism (Klemm and Markkanen, 2011, p. 95), or tourism of special interest (Soleimani, et al., 2019), but also a form of professional or mass tourism (Pásková, Budinská and Zelenka, 2021).

In fact, there is a certain formalization of astrotourism and it is not just about dedicated sites, such as astrotourism.com, which group information about places, experiences, services in the field, but something more.

Remarkable in this regard is "the Declaration in Defense of the Night Sky and the Right to Starlight" of 2007 (Starlight Conference, 2021), this year having the First International Congress (Conference) of Astrotourism, which took place at the University of Evora (Portugal), followed by another, respectively 2021 IDA Global Conference (online).

In the same context, attempts are being made to create a legal framework for the protection of certain destinations ("dark sky places") for astronomical observations "where views of the galaxies draw thousands of visitors per year" (Eskins, 2021), and several professional associations are active in field (for example, International Dark-Sky Association/IDA), founded in 1988.

In regard to the second notion, space tourism, even in this case the center of gravity concerning the criterion of definition migrated between motivation, transport and even the means of private / public transport.

In this way, general references such as Britannica give an updated definition: space tourism deals with "recreational space travel, either on established government-owned vehicles such as the Russian Soyuz and the International Space Station (ISS) or on vehicles fielded by private companies" (Seedhouse, 2021).

Another definition has as criterion the transport in outer space, in this situation space tourism being defined as a spatial component of it: "Space tourism is another niche segment of the aviation industry that seeks to give tourists the ability to become astronauts and experience space travel for recreational, leisure, or business purposes" (Henderson and Tsui, 2019). The "niche" segment is justified in this case, not by the preference related to the experience itself (of an extreme nature), but by the exclusivity of the extremely high costs, that not everyone can afford.

Von der Dunk (2011, p. 147) evaluates space tourism as "a New Kid on the Block" and gives a possible definition, as follows: "a proper private suborbital spaceflight, where the main aim is to offer private persons the possibility to fly on board private vehicles from one place to another, in the process entering, traversing and leaving the edge of outer space for the purpose of making enormous time gains", where "private spaceflight" is determined as: "Flights of humans intended to enter outer space (a) at their own expense or that of another private person or entity, (b) conducted by private entities, or (c) both" (Ibidem). It is more than obvious to emphasize the private component, but the definition is limiting by fixing the "ourist destination" only in the suborbital space (see also Chang, 2020; Savino, et al., 2013).

However, the reality of the present has exceeded the structure of this definition, as demonstrated by the last space "mission" for tourist purposes, Inspiration 4, the flight being orbital.

Consequently, it is justified to suggest a new term - exotourism - to capture the ongoing reality in a better way.

\subsection{Dimensions and relations}

Both forms, "astrotourism" and "space tourism", involve a number of dimensions, as follows:

a) both are forms of militant tourism, which promote social and civilizational values; 
While space tourism supports, through its capacity of manifestation, the idea of looking for an alternative for the human species (the possibility of colonizing a nearby planet, such as the programs for Mars), if the Earth would no longer be habitable or in an attempt to avoid a cosmic hazard (collision with an asteroid), astrotourism supports the intercultural dialogue, popularization of science (in general and astronomy, in particular), the fight against air pollution (especially against artificial light) and absolutely for climate change mitigation and militates for the right to a dark sky, seen as a legacy of humanity (see, in this sense, the declaration-manifesto from La Palma (2007), respectively "the Declaration in Defense of the Night Sky and the Right to Starlight" (Starlight Conference, 2021), mentioned earlier.

As an example, in terms of light pollution, respectively the increase of artificial light at night, due to the "lighting revolution" (from incandescent bulbs to LEDs), in order to improve the energy efficiency, it increases by $2.2 \%$ per year (the analyzed period being 2012-2016), as demonstrated by Kyba, et al. (2017, pp. 1-8). Due to this type of light alteration, the center of our Galaxy, the Milky Way, can no longer be observed by more than a third of the world's population (respectively $60 \%$ of Europeans and about $80 \%$ of North Americans) is the conclusion which another study reached (Falchi, et al., 2016, pp. $1-25)$.

\section{b) there are also forms of scientific (professional) tourism;}

It is enough to say that many of the forerunners of space tourism did not consider themselves as "tourists", although they were not sent on any government mission, with military, strategic or civilian character, even if they flew in such crews of professional astronomers, they did not have official assignments and, moreover, financing their own space flight. For example, Mark Shuttleworth, the first South African that traveled in space in 2002, the second "space tourist" after Denis Tito, used the expression "pioneer of commercial space travel", justifying by training and similar preparation (Knight, 2002). Likewise, Gregory Olsen, who flew in 2005, prefers the expression "private researcher" (Boyle, 2004), and Anousheh Ansari (2006), "private space explorer". Richard Garriott, who flew aboard the Russian Soyuz rocket in 2008, liked to be called a "private astronaut" (Garriott, 2008), and Guy Laliberté, who landed on the ISS in 2009, Russian cosmonaut Maksim Surayev used the expression "participant in the mission" (Writers, 2009). There are also opinions according to which even the participants in the last Inspiration 4 orbital journey cannot be considered "tourists", but "citizen explorers", "private astronauts" or anything else (Tumlinson, 2021).

It is also important to mention that both NASA and the Russian Federal Space Agency use the phrase "spaceflight participant" for any non-professional astronaut who travels in outer space and has no official duties, of a technical nature, on board. But when it comes to fully automated capsules that do not require a human crew to fly, as was in the case with Jeff Bezos' flight? It is another proof that the actual reality is slightly different from what has happened so far. The US Federal Aviation Administration also used the "commercial astronaut" distinction, but for the test pilots of the new SpaceShipOne and Two spacecraft.

Regarding astrotourism, there are also amateur astronomers who travel for scientific purposes to make certain observations during visible astronomical events on Earth (meteor showers, solar eclipses or simply to make observations of various celestial bodies).

c) both have a leisure component;

It promotes scientific observations for pleasure, not only for professionals, but also for the general public in order to raise awareness of both scientific values, and the Earth, as a planet, as a cosmic organism.

d) there are also forms of responsible tourism;

In the case of astrotourism, the implications on the environment are minimal, astrotourists being "those who only want to look at the stars" (Sanchez and Churm, 2021), while in space tourism, thanks to the latest technologies, have begun to be used missiles and reusable capsules (!).

e) considering the pandemic context 2020-2021, the two forms of tourism (with the amendment of the exclusivity of space tourism) initiated responses to tourism-phobia, generated by the restrictions against human mobility in general and the measures against the spread of COVID-19, which means that it can contribute to the revitalization of tourism activity (especially astrotourism, as a mass phenomenon). 
Astrotourism, unlike space tourism, has, in addition, other dimensions:

- it is also a form of ecotourism (celestial ecotourism at Weaver, 2011, pp. 38-45), not involving relevant effects on the environment;

- in this context, it also includes the virtual component, respectively tours in outer space, without leaving the Earth (Damjanov and Crouch, 2019, pp. 117-120);

- $\quad$ it is an instrument of sustainable development, by militating for a clear dark sky, for economic and energy sustainability, environment and biodiversity;

- it is an instrument of local economic development, by attracting tourists and capital to various places on Earth, from where astronomical observations can be made, especially of rural communities, astrotourism-specific destinations predominating in rural areas, which could prevent, in time, their depopulation; in this context, rural astrotourism has been conceptualized as an innovative strategy in the development of rural tourism (Fernández Hernández and Castañeda Pérez, 2016) or as a catalyst for rural development (Wyk-Jacobs, 2018);

- it is also a factor of the quality of human life, regarding the spiritual recovery and the soul relaxation that astrotourism implies.

\subsection{Destinations and tourist flow}

IDA (2021) identified 180 astrotourism destinations (over 90\% located in Anglo-Saxon North America and Europe), five in Asia (two in China and one each in Israel, South Korea, Japan), three in Australia, three in New Zealand, two in Africa (Namibia, South Africa), one in South America (Chile), to which are added two destinations from Oceania (Pitcairn Islands, British territory, and Niue), which can be grouped into five categories: 1. International Dark Sky Communities (settlements that have coherent policies to reduce artificial lighting at night and educate the population about the importance of access to a dark sky); 2. International Dark Sky Parks (public or private parks where astrotourism is practiced); 3. International Dark Sky Reserves (sparsely populated places, where astrotourism activities are also practiced); 4. International Dark Sky Sanctuaries (are the most isolated and sometimes the darkest places on Earth) and 5. Urban Night Sky Places (urban or quasi-urban sites with a high astrotourism potential).

Regarding the quantitative dimension of the tourist flow generated by astrotourism, here are just a few examples: 20 million adults traveled to see the 2017 US solar eclipse (University of Michigan's Institute for Social Research, 2017 cited in Carey, 2019), and 300,000 people traveled to the Atacama Desert (although expectations were 400,000) for the 2019 solar eclipse in Chile (Deutsche Welle, 2020).

\section{Methodology}

The results of this study are based on the extensive and critical analysis of the specialized literature, to summarize, firstly, the phenomenology related to space tourism in general, and secondly, to clarify terminological confusions, at least two terms are being used in this context, respectively "astrotourism" and "space tourism". As both manifest a series of shortcomings and no longer capture the reality "from the field", as it presents in manifestation now, we suggest a new notion, respectively exotourism, which seems to respond better to the new phenomenology of tourism in space.

Obviously, there are mentions according to which we cannot even talk about tourism in outer space, but the qualitative analyses and data provided by the companies involved in the new space race create the premises for the conceptual crystallization of exotourism.

Being an incipient phenomenon in progress, no quantitative analyses were used, although a series of reports and financial forecasts related to space industry in general are published.

\section{Results}

\subsection{Premise}

Cosmic space tourism, until recently a utopia, is about to become, if it has not become yet, a current reality. At least the introductions have been made. Space travelers, civilians, without being engaged in any governmental or private space mission, with tasks of a technical or scientific nature, have exceeded 
the upper limit of the mesosphere (vertical layer of the Earth's atmosphere), where, in terms of space transport, at about $100 \mathrm{~km}$ altitude (the so-called Kármán line), the density of the Earth's atmosphere becomes so low (in the ionosphere, atmospheric layer located above the mesosphere) that it makes the transition to the cosmic "vacuum". This conventional limit is, moreover, the limit from which a spacecraft is considered that re-enters the Earth's atmosphere and which involves a series of special conditions (a special friction force generated by the higher density of air molecules, high temperatures, etc.). For comparison, a normal flight by plane takes place at a cruising altitude of about $10 \mathrm{~km}(10,000$ $\mathrm{m})$.

As such, leaving the Kármán line already means orbital flight (Low Earth Orbit/LEO), currently successfully testing suborbital flights for civilians, but also being scheduled flights in interplanetary space (Fig. No. 1) with civilians (program "Dear Moon Project", which will be accomplished by the company SpaceX, in 2023, and will involve a singular loop around the Moon).

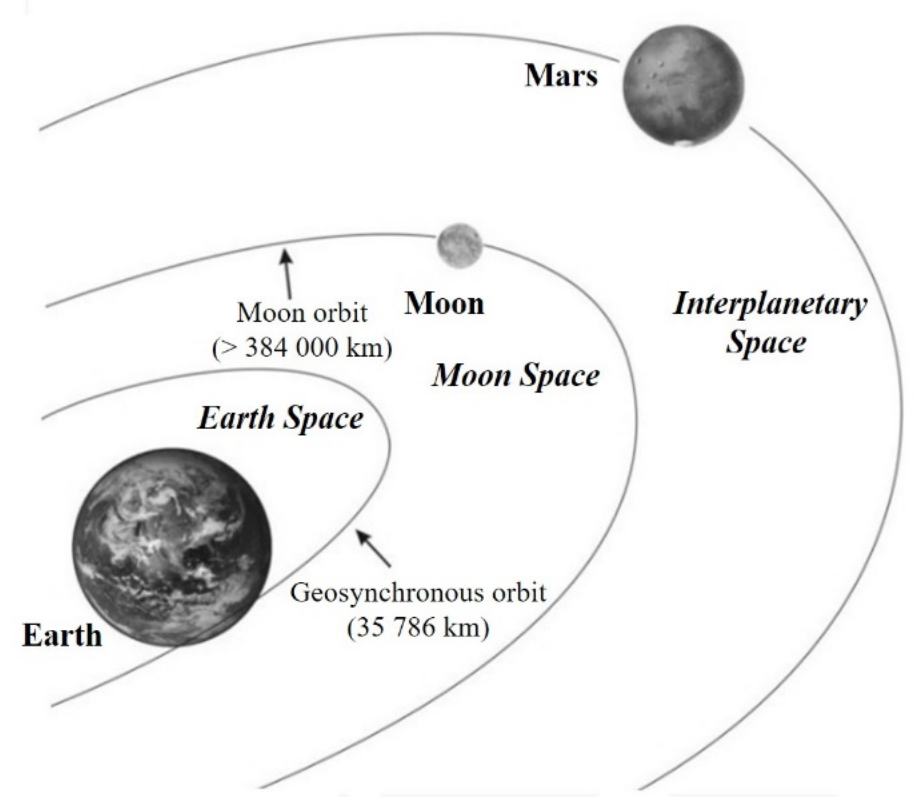

Fig. no. 1: Space of exotourism

Source: processed by author

\subsection{Brief history of exotourism}

Exotourism is in an emerging phase, being an extremely recent phenomenon, even in the history of modern tourism, the first exotourist can be considered the American billionaire Dennis Tito, who spent 8 days on the ISS in 2001. This is the "zero moment" of the birth of exotourism. However, despite the extremely short history - two decades - some evolutionary stages can still be identified (Table no. 1). Accordingly:

a) Exotourism 1.0: is the beginning phase of exotourism (2001-2009), consisting of a series of orbital flights, operated through the company Space Adventures, profiled on commercial space flights, costing between 20 and 35 million dollars. All these flights were performed with the Russian Soyuz rockets, the exostays taking place on the ISS, with an average duration of approximately 10 days. Exotourists have been joined into various government space missions, having previously completed training similar to that of professional astronauts, but without technical or scientific assignments on board, paying for their seats. As records, we indicate the first woman as an exotourist (Anousheh Ansari) and the first exotourist with two active exostays (Charles Simonyi, 2007 and 2009).

b) Exotourism 2.0: represents the privatization phase of space travel. In 2021, the first private suborbital flights took place, which meant: privately funded non-governmental missions, operated by two private companies (Virgin Galactic and Blue Origin), in the second case with their own space rocket and capsule , fully automated, without the need for professional pilots on board (as was the July 20 flight of Jeff 
Bezos). In the first case, Richard Branson's July 11 suborbital flight was made by a spaceplane operated by human crew.

c) Exotourism 3.0: is the current phase of privatization and commercialization of orbital flights, on September 16, 2021, taking place Inspiration 4: private launch, for commercial purposes, with its own technology, of a capsule in low Earth orbit, at a higher altitude than the ISS, a space trip in which four exotourists participated.

Table no. 1: Phases in the evolution of exotourism

\begin{tabular}{|c|c|c|c|}
\hline \multicolumn{2}{|r|}{ Stage } & \multirow{2}{*}{$\begin{array}{l}\text { Exotourism } \\
\text { destination }\end{array}$} & \multirow{2}{*}{ Exotourists/Time spend in space/Costs per seat (\$) } \\
\hline Years & Phase & & \\
\hline $\begin{array}{l}2001- \\
2009\end{array}$ & \multirow[t]{2}{*}{$\begin{array}{l}\text { Exotourism } 1.0 \\
\text { (Earth orbit) }\end{array}$} & \multirow[t]{2}{*}{$\begin{array}{c}\text { International } \\
\text { Space Station } \\
\text { (ISS, } 450 \mathrm{~km} \\
\text { medium altitude) }\end{array}$} & $\begin{array}{l}\text { 1. Dennis Tito/8 days }(2001) / 20 \text { million } \\
\text { 2. Mark Shuttleworth/10 days }(2002) / 20 \text { million } \\
\text { 3. Gregory Olsen/10 days }(2005) / 20 \text { million } \\
\text { 4. Anousheh Ansari/10 days }(2006) / 20 \text { million } \\
\text { 5. Charles Simonyi/10 days }(2007) / 20 \text { million } \\
\text { 6. Richard Garriott/13 days }(2008) / 30 \text { million } \\
\text { 7. Charles Simonyi/14 days }(2009) / 30 \text { million } \\
\text { 8. Guy Laliberté/12 days }(2008) / 35 \text { million }\end{array}$ \\
\hline 2021 & & & $\begin{array}{l}\text { (...) Planned } \\
\text { Yusaku Maezawa, Yozo Hirano/12 days (planned on } \\
\text { December) }\end{array}$ \\
\hline 2021 & $\begin{array}{l}\text { Exotourism } 2.0 \\
\text { (sub-orbital) }\end{array}$ & $\begin{array}{c}\text { Sub-orbital } \\
\text { spaceflight } \\
\text { (Kármán line) } \\
\end{array}$ & $\begin{array}{l}\text { 9. Richard Branson/1,5 hours (July 11) } \\
\text { 10. Jeff Bezos, Mark Bezos, Oliver Daemen, Wally Funk/ } \\
10 \text { minutes and } 10 \text { seconds (July 20)/ }\end{array}$ \\
\hline 2021 & Exotourism 3.0 & $\begin{array}{l}\text { Low Earth Orbit } \\
\text { (over } 130 \mathrm{~km} \\
\text { above ISS) }\end{array}$ & $\begin{array}{l}\text { 11. Jared Isaacman, Sian Proctor, Hayley Arceneaux } \\
\text { Christopher Sembroski/8 days (September)/55 million }\end{array}$ \\
\hline $\begin{array}{c}(\ldots) \\
2023\end{array}$ & $\begin{array}{l}\text { Exotourism } 4.0 \\
\text { (beyond Earth } \\
\text { orbit) }\end{array}$ & $\begin{array}{c}\text { Moon } \\
\text { (Moon space) }\end{array}$ & $\begin{array}{l}\text { (...) Planned } \\
\text { Yusaku Maezawa, ”Dear Moon Project” (SpaceX) }\end{array}$ \\
\hline $\begin{array}{l}2024- \\
2026\end{array}$ & $\begin{array}{l}\text { Exotourism } 5.0 \\
\text { (other planets) }\end{array}$ & $\begin{array}{c}\text { Mars } \\
\text { (interplanetary } \\
\text { space) }\end{array}$ & $\begin{array}{l}\text { (...) Planned } \\
\text { - SpaceX first uncrewed flight (2024) } \\
\text { - SpaceX first crewed flight (2026) }\end{array}$ \\
\hline
\end{tabular}

Source: BBC (2001), Carreau (2008), The Guardian (2009), Berger (2021), Street (2021), Foust (2021)

These three stages represent certainties, things that have already happened, but in the very near future, other space trips are planned, also private, for commercial purpose, which hints at two further phases of the evolution of exotourism, such as:

d) Exotourism 4.0: commercial travel for tourist purposes beyond Earth's orbit, into the lunar space or on the surface of the Earth's natural satellite (see "Dear Moon Project", by Japanese billionaire Yusaku Maezawa, a SpaceX flight with its own technology, scheduled for 2023) and

e) Exotourism 5.0: space travel in interplanetary space, being in progress several projects for Mars, starting with 2024-2026.

\subsection{Types of exotourism}

From the evolution of exotourism as a phenomenon, a classification of exotourism types can be made, according to "destination", as follows:

I. suborbital exotourism: the imponderability and the extraordinary view on the planet from the "horizon" of the terrestrial atmosphere are experienced; the duration may be of some minutes, while the launching, recovering and re-entering the atmosphere or landing, as the case may be, taking place in a single day; the first tests were executed in 2004 by professional test pilots, without tourists on board (SpaceShipOne, two flights, $100 \mathrm{~km}$, respectively $112 \mathrm{~km}$ altitude), the first commercial departings for tourist purposes being occured in 2021 .

II. orbital exotourism: involves a longer duration, at least a few days, in which sudden accelerations and high gravitational forces are experienced, which require special physical training; for 2023, the Space Adventures company has planned a flight with Soyuz on the International Space Station with 
exotourists, in order to experience the free exit into outer space (spacewalk); the first orbital flight, which involved a "civilian" was in 2001, with Denis Tito.

III. Moon space exotourism: the first trip, for tourist purpose, out of Earth orbit, is already planned for 2023 and will be a loop around the Moon, operated by SpaceX (Elon Musk's company) and funded by the Japanese billionaire Yusaku Maezawam, alongside with which will board the Starship rocket (in development, $120 \mathrm{~m}$ high, $9 \mathrm{~m}$ in diameter, mass 5,000 tons, reusable, bigger than Saturn V, the record in the field), eight more tourists. It is estimated that the lunar exotourism will have third components: a) a singular loop around the moon, b) circumlunar flight (in lunar orbit) and c) landing.

The idea is a bit older, for example: "In 1968, Pan Am started taking reservations for a shuttle to the moon. By the time the program was discontinued three years later, more than 90,000 signatures had been collected" (Verdon, 2021). But in 2024 (maximum 2028), the ISS will be decommissioned after reaching its life expectancy, currently being designed and developed Lunar Gateway (funded by NASA), practically a future international circumlunar space station.

IV. interplanetary space exotourism: SpaceX's first interplanetary space flights are scheduled for 2024 (unmanned) and 2026 (manned).

\subsection{Definition and characteristics}

As I mentioned before, the two notions used so far in the specialized literature - astrotourism and space tourism - are no longer satisfactory in terms of explaining the current reality, the emergence of trade and privatization of outer space generating new situations.

Thus, a more comprehensive notion is that of exotourism, with the following meanings:

- to be an extension of tourism in outer space;

- to capture the phenomenology associated with a journey that goes beyond the classic airspace ("exo" - outside the Earth);

- the lower limit can be considered the Kármán line (about $100 \mathrm{~km}$ altitude), that is the limit from which aspects specific to a space flight begin to be felt (eg. imponderability/zero gravity, observation of the atmospheric horizon and the curvature of the globe or re-entry into dense terrestrial atmosphere);

- to involve a journey of pleasure and spiritual experimentation of leaving the Earth's surface and observing it from high altitudes;

- not to involve professional, remunerated duties.

As in the case of traditional tourism, respectively the action of traveling, without determining material interest, in order to recover physically or intellectually (see also Cocean, Vlăsceanu and Negoescu, 2005; Negut, 2004), there will certainly be hints related to many aspects, including in terms of time spent, as this new form of tourism evolves. For example, there is a difference between suborbital flights (which can only last a while, from the moment they reach an altitude of $100 \mathrm{~km}$ until they re-enter the dense terrestrial atmosphere - the only landmark in this regard being the recent flights of Richard Branson and Jeff Bezos) and the orbital ones involving "overnight stays" on the ISS or future "space hotels".

Consequently, exotourism represents the entire phenomenology associated with activities related to space travel (suborbital, orbital and extraorbital), for recreational purposes, with public or private means self-financed or privately financed (donations).

As a result, exotourism is different from astrotourism (which captures, in particular, the terrestrial dimension of activities related to astronomical observations) and is also different from space tourism, surpassing terrestrial space (with reference to suborbital and orbital flights), in 2023 being scheduled the flight of the first "civilians", or let's entitle them as "exotourists", around the Moon.

For the moment, exotourism is an incipient, niche form, exclusive in terms of costs, special training and the extreme nature of the experience (which brings it closer to adventure tourism), but the dynamics of this phenomenon in the last two years foresee at a possible future "mass character". The cosmic competition during the Cold War (with military and strategic character), ended with the landing in 1969, 
today has a commercial and private dimension, both as methods and as participation, creating the premises for amplifying the exotourism phenomenon. In the past, only the states could afford a space flight, today this represents the privilege of individuals (it is true, billionaires, eccentrics), but a cheaper exotourism will come from its marketing like any other tourism product on a larger scale.

\section{Conclusions}

Following the analysis of the concept of exotourism, the following conclusions emerged:

- Exotourism subscribes to a new phenomenology, different from everything that has been so far in the history of space flight. The spatial phase of history has entered an accentuated dynamic currently, with new state space actors (emerging: UAE, Israel, Turkey, etc., in addition to the established traditional ones, such as USA, Russia, China, India, Japan, etc.) and non-state (private companies like SpaceX, Blue Origin, Virgin Galactic, ONs, foundations, layer-ups or simply eccentric billionaires who invest heavily in the space industry) that made possible the commercialization and privatization of outer space. As a result, the first private space flights have been executed for recreational purposes, and others are scheduled, which could represent a new form of tourism, namely exotourism.

- From "missions in outer space" (with military, strategic or technical-scientific character) to "travel in outer space" (for recreational purpose). In 2021 took place the first cosmic flights (sub-orbital and orbital) with private character (self-financed), with their own technical means (sometimes, fully automatic without human crew) and with "civilian" participants who wanted to experience the spatial journey. These "exotourists" differ from the first "space tourists" (since the early 2000s), who flew in the organization of professional crews and within government missions. Also, for the year 2023 is scheduled the first flight in the lunar space, for tourist purposes.

- Exotourism is a component of exoeconomics. As a notion, exotourism is part of a wider theoretical structure, recently developed in academic debates, such as exoeconomics (space economics), exobusiness (business related to the new space race), to which could be added other dimensions, respectively exopolitics and exostrategy.

- Exotourism is different from astrotourism (astronomical tourism). While the first one tries to capture the phenomenology associated with travel in outer space (sub-orbital, orbital and extraorbital), the second one refers in particular to the terrestrial dimension of travel for astronomical observations (meteor showers, eclipses of the Sun, the observation of cosmic bodies, etc.) and even the launching of spacecraft.

- Exotourism is also different from space tourism. Until now, space tourism has been a niche segment of the space industry, during government missions in outer space, "sneaking" a space "tourist", who paid his place, to spend a few days on the ISS. The start of suborbital and orbital "pleasure" travel, so for tourist purpose, was set recently in 2021, such as Inspiration 4, the first orbital trip with exclusively "civilian" participants (operated by SpaceX).

- Exotourism preserves a part of the dimensions of the precursor forms of tourism (astrotourism and space tourism), among which we mention the militant character (by promoting universal values), thematic (scientific-professional), responsible, adventurous.

- Exotourism is an incipient, niche form, unique in terms of costs, special training and the extreme nature of the experience.

- Exotourism is in the process of crystallization and conceptual individualization. With the two precursor forms (astrotourism and space tourism), including definition, specialized terminology, components and characteristics, there is an incipient theoretical structure in which exotourism can be analyzed, as a form of neotourism. 


\section{References}

Altschuler, W., 2019. Is Astrotourism The Next Big Thing? Incredible Nighttime Outdoor Adventures For Stargazers. [online] Available at: <https://www.forbes.com/sites/wendyaltschuler/2019/08/31/isastrotourism-the-next-big-thing-incredible-nighttime-outdoor-adventures-for-stargazers/?sh=4b96705f $\underline{51 \mathrm{~d} 3}>$ [Accessed 22 September 2021].

Amos, J., 2001. Virgin Galactic: Sir Richard Branson rockets to the edge of space. [online] Available at: $<$ https://www.bbc.com/news/science-environment-57797297> [Accessed 24 September 2021].

BBC, 2001. Profile: Tito the spaceman. [online] Available at: $<$ http://news.bbc.co.uk/2/hi/science/nature/129792 $\underline{4 . s t m}>$ [Accessed 24 September 2021].

Berger, E., 2021. SpaceX announces first "free flyer" human spaceflight. [online] Available at: $<\underline{\text { https:// }}$ arstechnica.com/science/2021/02/spacex-announces-first-free-flyer-human-spaceflight/> [Accessed 24 September 2021].

Boyle, A., 2004. Space millionaire to mix science with pleasure. [online] Available at: https://www.nbcnews.com/ id/wbna4623674> [Accessed 27 September 2021].

Carreau, M., 2008. Profile: Tito the spaceman. [online] Available at: $<\$ 30$ million buys Austin resident a ride on Soyuz mission> [Accessed 24 September 2021].

Chang, E.Y.W., 2020. From aviation tourism to suborbital space tourism: A study on passenger screening and business opportunities. Acta Astronautica, [e-journal] 177(December), pp. 410-420. 10.1016/j.actaastro. 2020.07.020.

Cocean, P., Vlăsceanu, G., Negoescu, B., 2005. Geografia general a turismului. București: Meteor Press.

Damjanov, K. and Crouch, D., 2019. Virtual Reality and Space Tourism. In: E. Cohen and S. Spector, ed. 2019. Space Tourism: The Elusive Dream (Tourism Social Science Series, Vol. 25). Bingley Emerald Publishing Limited. Ch.5.

Deutsche Welle, 2020. Total solar eclipse wows people in Chile, Argentina. [online] Available at: $<$ https://www.dw.com/en/total-solar-eclipse-wows-people-in-chile-argentina/a-55942837> [Accessed 22 September 2021].

Dunk von der, F.G., 2011. Space Tourism, Private Spaceflight and the Law: Key Aspects. Space Policy, [e-journal] 27(2011), pp.146-152. 10.1016/j.spacepol.2011.04.015

Eskins, J., 2021. State-Protected Dark Skies Could Change Astrotourism Forever. [online] Available at: $<$ https://www.cntraveler.com/story/stargazing-tourism-is-the-next-big-thing-for-these-states $>$ [Accessed 22 September 2021].

Falchi, F., Cinzano, P., Duriscoe, D., Kyba, C.C.M., Elvidge, C.D., Baugh, K., Portnov, B.A., Rybnikova, N.A. and Furgoni, R., 2016. The new world atlas of artificial night sky brightness. Science Advances, [e-journal] 2(6), pp.1-25. 10.1126/sciadv.1600377.

Fayos-Solá, E., Marín, C. and Jafari, J., 2014. Astrotourism: No requiem for meaningful travel. Revista de Turismo y Patrimonio Cultural, [e-journal] 12(4), pp.663-671. 10.25145/j.pasos.2014.12.048.

Fernández Hernández, C. and Castañeda Pérez, A. I., 2016. Astroturismo Rural: una estrategia de innovación en destino a partir de la tematización en turismo rural en la isla de La Palma, XIX Congreso AECIT. Tiempos de cambios en el turismo. Adeje, Tenrerife (Islas Canarias), 16-18 November 2016. Castellón de la Plana/Almeria: Asociación Española de Expertos Científicos en Turismo.

Foust, J., 2021. Japanese billionaire, Russian actress to fly to ISS. [online] Available at: <https://spacenews.com/ japanese-billionaire-russian-actress-to-fly-to-iss/> [Accessed 25 September 2021].

Garriot, R., 2008. Do Not Call Me a Space Tourist!. Richardinspace, [blog] 31 January. Available at: $<$ https://web.archive.org/web/20090627164655/http://www.richardinspace.com/index.cfm?fuseaction= blog. welcome\&theyear $=2008 \&$ themonth $=1 \&$ view $=18>$ [Accessed 27 September 2021].

Henderson, I.L., Tsui, W.H.K., 2019. The Role of Niche Aviation Operations as Tourist Attractions. In: Graham, A. and Dobruszkes, F., eds. 2019. Air Transport: A Tourism Perspective. Amsterdam (Netherlands)/ Oxford (UK)/Cambridge (USA): Elsevier. Ch.17. 
Howell, E., 2021. SpaceX's Inspiration4 all-civilian spaceflight: When to watch and what to know. [online]

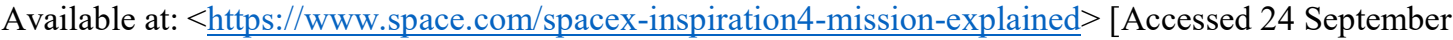
2021].

International Astronomical Union's European Regional Office of Astronomy for Development, 2021. A Design Manual forAstro-Tourism Experiences. [online] International Astronomical Union's European Regional Office of Astronomy for Development. Available at: $<$ https://astro4dev.eu/images/main/Astrotourism manual_ENG 150dpi.pdf> [Accessed 24 September 2021].

IDA, 2021. International Dark Sky Places. [online] Available at: < https://www.darksky.org/ourwork/conservation/idsp/> [Accessed 22 September 2021].

Klemm, G., Markkanen, S., 2011. Space Tourism. In: Papathanassis, A., ed. 2011. The Long Tail of Tourism. Holiday Niches and their Impact on Mainstream Tourism. Wiesbaden: Gabler. Ch.11.

Knight., W., 2002. "Space tourist" insists on pioneering role. [online] Available at: <https://www.newscientist.com/ article/dn2190-space-tourist-insists-on-pioneering-role/?ignored=irrelevant $>$ [Accessed 27 September 2021].

Kyba, C.C.M., Kuester, T., de Miguel, A.S., Baugh, K., Jechow, A., Hölker, F., Bennie, J., Elvidge, C.D., Gaston, K.J. and Guanter L., 2017. Artificially lit surface of Earth at night increasing in radiance and extent. Science Advances, [e-journal] 3(11), pp.1-8. 10.1126/sciadv.1701528.

Kunjaya, C., Melany, Sukmaraga, A. A. and Arsono, T., 2019. Possibility of astronomical phenomena to be used to support tourism industry. Journal of Physics: Conference Series, Volume 1231, 10th Southeast Asia Astronomy Network 18-21 October 2018, Lampung, Sumatera, Indonesia, [e-journal] 1231(012025), pp.1-9. 10.1088/1742-6596/1231/1/012025.

Neacșu, M.C., Matei, D., (in press) Concepte emergente: exopolitică, exostrategie, exobusiness. In: Neacșu, M.C., ed., (in press) 30 de ani de la sfârșitul Războiului Rece. București: Ed. ASE. Ch.4.

Neguț, S., 2004. Geografia turismului. București: Meteor Press.

Pásková, M., Budinská, N. and Zelenka, J., 2021. Astrotourism-Exceeding Limits of the Earth and Tourism Definitions?. Sustainability, [e-journal] 13(1), pp.1-25. 10.3390/su13010373.

Rincon, P., 2001. Jeff Bezos launches to space aboard New Shepard rocket ship. [online] Available at: <https:// www.bbc.com/news/science-environment-57849364> [Accessed 24 September 2021].

Sanchez, E. and Churm, P.A., 2021. Stargazers flock to 'astrotourism' event in Évora, Portugal. [online] Available at: <https://www.euronews.com/2021/09/19/stargazers-flock-to-astrotourism-event-in-evora-portugal> [Accessed 22 September 2021].

Savino, R., Russo, G., Carandente, V. and D’oriano, V., 2013. Hyplane: Challenges for Space Tourism and Business Transportation. Journal of Aeronautics \& Aerospace Engineering, [e-journal] 2(5), pp. 1-8. 10.4172/2168-9792.1000123.

Seedhouse, E., 2021. Space tourism. [online] Available at: <https://www.britannica.com/topic/space-tourism> [Accessed 24 September 2021].

Singh, U., 2021. India's Ministry of Tourism looks up to the stars to showcase the latest form of nature-based travel. [online] Available at: $<$ https://www.outlookindia.com/outlooktraveller/travelnews/story/71160/ dekho-apna-desh-webinar-series-explores-astro-tourism $>$ [Accessed 22 September 2021].

Soleimani, S., Bruwer, J., Gross, M.J. and Lee, R., 2019. Astro-tourism conceptualisation as special-interest tourism (SIT) field: a phenomonological approach. Current Issues in Tourism, [e-journal] 22(18), pp. 2299-2314. 10.1080/13683500.2018.1444021.

Space Adventures, 2021. MZ Mission to the ISS. [online] Available at: <https://spaceadventures.com/ms-20/> [Accessed 25 September 2021].

Starlight Conference, 2021. The I International Astrotourism Conference. [online] Available at: $<$ https://internationalstarlightconference.com/> [Accessed 22 September 2021].

Stimac, V., 2020. What is Space Tourism? A New Definition. [online] Available at: $<$ https://spacetourismguide. com/space-tourism-definition> [Accessed 22 September 2021].

Street, F., 2021. First space tourist Dennis Tito. [online] Available at: $<$ https://edition.cnn.com/travel/article/ space-tourism-20-year-anniversary-scn/index.html > [Accessed 24 September 2021]. 
Șapera, A., 2021. Exostrategy and Space Industry 4.0. [webinar] 9 March and 6 April. Bucharest: Bucharest University of Economic Studies (MA Geopolitics and Business).

Șapera, A., 2015. Exoeconomie. Dezvoltarea economiei extraplanetare. In: Stan, M., Gavrilă, B., eds. 2015. România noului val. Bucharest: Civil Society Resource Center. pp. 357-363.

Șapera, A., 2013. Towards Exoeconomics - Developing an off-planet economy and its implications. [online] Available at: <http://www.fgdb.ro/assets/resurse/Andrei-Sapera-Exoeconomics-2013.pdf> [Accessed 26 September 2021].

The Guardian, 2009. Circus tycoon Guy Laliberté becomes first clown in space. [online] Available at: < $\underline{\text { https:// }}$ www.theguardian.com/science/2009/sep/30/guy-laliberte-clown-space-circus $>$ [Accessed 24 September 2021].

Tumlinson, R., 2021. Private astronauts are not 'space tourists' (op-ed). [online] Available at: <https://www. space.com/private-astronauts-are-not-space-tourists $>$ [Accessed 26 September 2021]

Verdon, M., 2021. Why the future of space tourism has finally arrived. [online] Available at: < https://www. robbreport.com.sg/why-the-future-of-space-tourism-has-finally-arrived/> [Accessed 28 September 2021].

Weaver, D., 2011. Celestial ecotourism: new horizons in nature-based tourism. Journal of Ecotourism, [e-journal] 10(1), pp. 38-45. 10.1080/14724040903576116.

Wilson, E.K., 2019. Space Tourism Moves Closer to Lift Off. Engineering, [e-journal] 5(5), pp.819-821. 10.1016/j.eng.2019.08.006.

Writers, S., 2009. Circus man ready to make 'fairy tale' come true in space. [online] Available at: https://www. space-travel.com/reports/Circus man_ready to make fairy tale come true in space 999.html> [Accessed 27 September 2021].

Wyk-Jacobs van, L, 2018. Astro-Tourism as a Catalyst for Rural Route Development. PhD. University of Pretoria. Available at: <https://repository.up.ac.za/bitstream/handle/2263/70036/VanWyk-Jacobs Astro 2018. pdf? sequence $=1 \&$ is Allowed $=\mathrm{y}>$ [Accessed 24.09.2021]. 